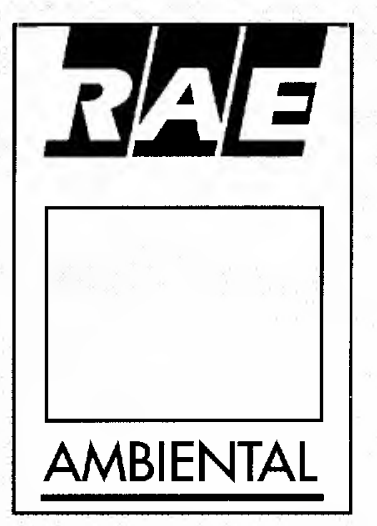

\title{
GERAÇÃO DE EMPREGOS E PRESERVAÇÃO DO MEIO AMBIENTE: O GRANDE DESAFIO
}

Soluções alternativas para o problema do desemprego causado pelo progresso técnico, através do desenvolvimento sustentável.

Some solutions to the unemployment problem caused by technical progress through the sustainable development.

PALAVRAS-CHAVE:

Desemprego, progresso técnico, exclusão social, meio ambiente, desenvolvimento sustentável.

\section{KEY WORDS:}

Unemployment, technical progress, social discrimination, environment, sustainable development.
*Coordenador do Núcleo de Assessoriá Técnica e Administrativa da EAESP/FGV.

**Coordenador do CEAMA Centro de Estudos de Administraçăo e Meio Ambiente da EAESP/FGV.

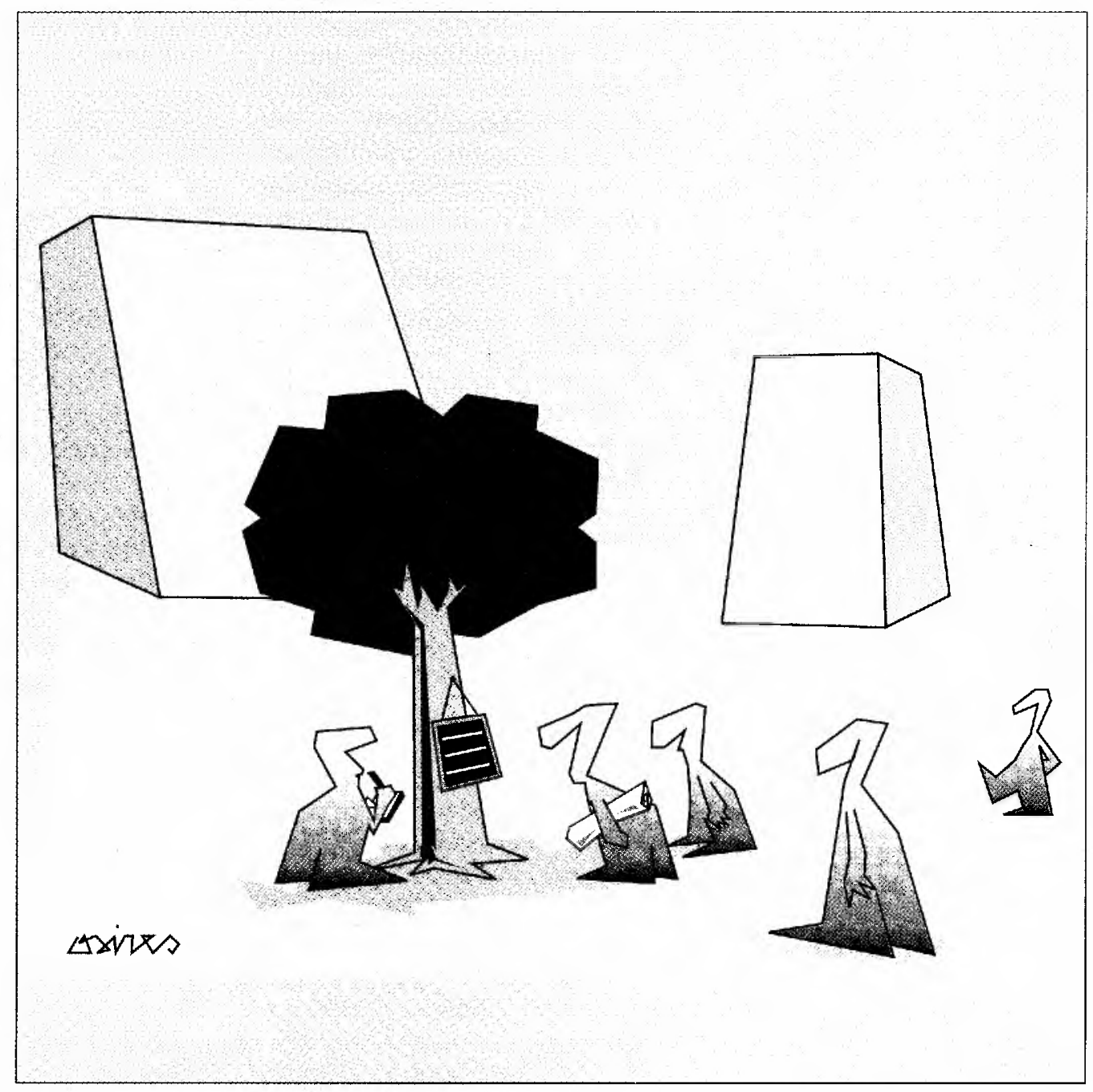

São Paulo, v. 34, n. 6, p. 73-79
*Walter Delazaro

**José Carlos Barbieri 
1. O OClO já passa dos limites. Exame, 23.06.94.

2. MORGAN, J. P. World Financial Markets. Maio/jun., 1993.

3. FERRAZ, Heitor. Em 68, queriam mudar o mundo. Agora, em 93, os estudantes brigam por emprego. Jornal da USP. 12.12.1993, p.15

4. RATTNER, Henrique. Tecnologia e Ecodesenvovimento. São Paulo em Perspectiva, v. 3, n. 4, p. 88-93, out./dez. 1989
O desemprego é, sem dúvida, um dos maiores problemas deste fim de século, um problema que afeta, hoje, todos os países, independentemente do seu grau de desenvolvimento. De fato, segundo artigo recente da revista Exame ${ }^{1}$, baseado em estudo da OCDE (Organização para a Cooperação e Desenvolvimento Econômico, que congrega 24 das economias mais industrializadas do mundo, 19 das quais européias), "nos anos 60, o indice de desemprego na Europa era de fazer inveja para o resto do mundo", não chegava a $2 \%$ da população economicamente ativa. Esse índice, no entanto, dobrou nos anos 70 e, novamente, nos anos 80 . A tendência nesta década é, ainda, de crescimento do desemprego ${ }^{2}$.

De acordo com Sachs, "nos paises do Mercado Comum Europeu, há cerca de 30 mithões de desempregados, sendo que um terço deles encontra-se nessa condição por mais de dois anos. Entre os $20 \%$ mais ricos, a renda média é sete vezes maior do que entre os $20 \%$ mais pobres". A taxa de desemprego entre os jovens é de 13\% e sua tendência é crescente. Referindo-se ao mesmo problema, que tem levado a manifestações de rua, artigo publicado no periódico da Universidade de São Paulo ${ }^{3}$ mostrava que os estudantes em 1968 lutavam para mudar o mundo, agora, brigam por emprego. $\mathrm{O}$ mesmo artigo da revista Exame, - O Ócio já passa dos limites - comenta que, na Europa, um a cada cinco jovens está sem ocupação, principalmente na França, Itália, Finlândia e Irlanda; na Espanha, um a cada três". Não é por outra razão que vários governos têm sido trocados ultimamente, como é o caso do Canadá, após ruidosas campanhas onde o desemprego constituiu o tema dominante. As tendências "nazifascistas" e populistas no mundo todo se nutrem das massas desempregadas. Estima-se que no mundo todo existam cerca de 800 milhões de desempregados. Não é por outra razão que o grupo dos sete países mais ricos (EUA, Japão, Alemanha, Itália, França, Reino Unido e Canadá) reuniram-se em Detroit em março de 1994 para, pela primeira vez, tratar exclusivamente do desemprego. Para os ministros da economia e do trabalho desses sete países, que são os mais industrializados do planeta, o nível atual de desemprego é o mais elevado após a grande depressão de 1929, que é considerado o maior de todo este sé- culo. Vale lembrar que a próxima reunião de cúpula da ONU para tratar do meio ambiente e desenvolvimento, a ser realizada em 1995, em Copenhague, terá como um dos temas centrais o desemprego.

Fatos como esses colocam a questão do desemprego como um problema explosivo, pois cria uma dicotomia injusta na sociedade, e adquire cada vez mais aspectos de uma enfermidade social crônica. No rastro desse, que já é um problema em si, outras graves questões sociais se agudizam, como, por exemplo, a proliferação de regiões urbanas e rurais decadentes, o aumento da violência, inclusive mais forte contra imigrantes, da prostituição e do crime organizado. O desemprego tem levado aos subúrbios das grandes cidades européias uma problemática semelhante àquela que antes parecia ser dos países do Terceiro Mundo: violência, drogas, racismo e exclusão social dos menos favorecidos. É necessário, portanto, uma meditação profunda sobre o tema, particularmente sobre o caso brasileiro, onde a solução do problema tem sido contínua e impunemente postergada.

A corrida desenvolvimentista, em que a humanidade se engajou neste século, tem levado à depauperação de recursos, e à degradação e destruição do meio ambiente. Denúncias e alertas no mundo inteiro sobre abusos e comportamentos irracionais dos agentes econômicos são muito numcrosos. Queimadas, erosão, poluição das águas, contaminação do solo por pesticidas, ar irrespirável em muitas conglomerações urbanas e cidades industriais constituem fenômenos graves, ameaçando a própria sobrevivência das populações". O afã do crescimento produtivo propalado pela produção em massa prometia, na opinião dos desenvolvimentistas, um aumento generalizado do padrão de vida a todo o mundo, inclusive aos países em desenvolvimento. Tal promessa se revelaria um engano, pois além de se levar ao Terceiro Mundo a poluição e a ameaça ao meio ambiente, sua gente, na grande maioria, não tem conseguido se empregar condignamente e continua vi- 
vendo à margem dos setores modernizados. E agora, a falta de empregos se avoluma, pelo sistema de produção implementado, mesmo nos países ricos, promovendo, desse modo, um retrocesso anteriormente inimaginável, na qualidade de vida de parcelas crescentes de seus habitantes.

Mesmo enquanto ocorre esse grave fenômeno econômico-social, a produção total não tem parado de crescer, pelo menos dentro de uma perspectiva de longo prazo. Nas economias desenvolvidas, com taxas altas, baixas ou crescentes de desemprego, o crescimento da produção industrial tem sido apreciável, para não se dizer espantoso. Há o exemplo do Japão, da Espanha mais recentemente, e mesmo dos EUA, que têm crescido consistentemente, $26 \%$ de aumento na produção industrial nos últimos 15 anos $^{\overline{5}}$.

Não cabe aqui discutir as causas do desemprego, assunto este polêmico e que comporta inúmeras interpretações. Um conjunto dessas causas refere-se, sem dúvida, às consequências do progresso técnico, aqui entendidas na sua concepção mais ampla, envolvendo não só novos processos produtivos e administrativos, como novas formas de organização do trabalho. A busca de novos padrões de competitividade tem levado as empresas a introduzirem novas técnicas de produção baseadas na microeletrônica, bem como novos sistemas ou concepções de gestão, que, a exemplo do JIT (Just-in-time), são intensificadores do trabalho individual e, por isso mesmo, poupadores de emprego. $\mathrm{O}$ resultado geral são sistemas de produção enxutos (lean production), altamente produtivos, que utilizam, porém, pouca mão-de-obra.

Os impactos dessas técnicas sobre o emprego ainda não são conhecidos em toda a sua totalidade. Como diz Feldmann, "a idéia de que a informatização e a automação geram melhores oportunidades no mercado de trabalho e contribuem para manter o nivel geral de emprego é uma hipótese dificil de comprovar"6. O autor conclui, com base em inúmeros trabalhos analisados, que a automação aumenta a produtividade e a qualidade dos bens produzidos, mas não aumenta a oferta de novos empregos. Para $o$ caso brasileiro, ele entende que esta situação é mais grave ainda, pois, a cada ano,

\section{Abuscade novos padrõ̃es de competituvidadetemlevado as empresas a intraduziremnovas técnicas de produção baseadas na microeletrônica bem comonovos sistemas ou concepcóes de gestão. que. a exemplo do لJI. são intensficicadores do trabalho individual e. por isso mesmo. poupadores deemprego.}

dois milhões de novos empregos devem ser gerados na cconomia, só para absorver o crescimento vegetativo da população.

Pode-se argumentar que os dados existentes não permitem afirmar de modo categórico que essas novas técnicas produtivas causam desemprego. Existem dúvidas sobre isso e as encontramos em praticamente todos aqueles que se propuseram a estudar o assunto. Tais dúvidas decorrem principalmente do fato de que os efeitos da introdução dessas novas técnicas podem se dar de modo defasado no tempo e no espaço. No entanto, tudo indica, $e$ as estatísticas de desemprego parecem confirmar, que a possibilidade de compensação entre novas oportunidades criadas pelas novas técnicas e os postos de trabalho poupados por elas dependem da possibilidade de crescimento contínuo da produção, um fato praticamente impossível de ocorrer, quer pelas limitações de mercado, quer pelas restrições impostas pelos ecossistemas. Questões como essas estão implicitamente mencionadas na Agenda 21 da Eco 92, quando trata da necessidade de criar novos padrões de consumo, uma vez que não é possível atender a população total com o mesmo padrão das classes ricas. Os recursos do planeta iriam se exaurir em curto período de tempo. Essa é uma questão crucial: como manter o crescimento econômico para atender toda a população do planeta com um padrão de fruição de bens compativeis com a dignidade humana, sem esgotar os recursos naturais?

$\mathrm{O}$ crescimento desenfreado da produção, mantendo-se o esforço individual atual com a sustentação de baixos índices
5. O MITO da Queda. Exame, 03.02.1993.

6. FELDMANN, Paulo Roberto. Robô: ruim com ele, pior sem ele. São Paulo: Trajetória Cułtural, 1988, p. 172-4. 
de desemprego, levará à exaustão de vários recursos naturais, a maioria deles concentrados em países do Terceiro Mundo. Trata-se, portanto, de uma corrida suicida. $O$ consumismo tem sido preconizado há décadas. Lebow, um analista de mercado dos anos 40, citado por Durning7, declarou logo após a segunda Guerra Mundial sobre os EUA: "nossa economia imensamente produtiva pede que façamos do consumo nosso meio de vida. Precisamos consumir, queimar, usar, substituir, descartar as coisas em proporção sempre crescente..." O apelo foi atendido em muitos lugares. Segundo esse autor, nos EUA de hoje, em relação a uma pessoa de 1950, o cidadão médio possui 2 vezes mais carros, percorre

\section{Ogrande desafio será, portanto.o de criar novos paradigmas de desenuolumento ondea preservação do meı ambıenteea promocãodoempregosefertilizen reciprocamente, formandoum círculouirtuoso.}

de carro 2,5 vezes mais quilometragem, usa 21 vezes mais plástico, viaja 25 vezes mais longe de avião. De 1960 a 1987, a percentagem das casas com ar condicionado passou de 15 a $64 \%$, e o número das casas com televisões em cores cresceu de 1 para $93 \%$. Para outros países e muitos outros produtos, Durning apresenta números estarrecedores de aumento de consumo. "O avanço da tecnologia, os ganhos crescentes e o barateamento dos bens materiais aumentaram o consumo no mundo todo em niveis jamais pensados um século atrás. As classes abastadas dos paises pobres tentam imitar o consumismo das economias altamente desenvolvidas, porém, muito antes que o mercado possa atingir o sonho norte-americano, o planeta estará devastado. Alimentação, madeira, fibras naturais eoutros produtos naturais usados por um holandês emprega cinco vezes mais terra fora do seu país do que dentro, sendo a maior parte do Terceiro Mundo". Nas últimas décadas, a partir de 1950 , a população mundial consumiu a mesma quanti- dade de produtos e serviços que todas as gerações anteriores juntas ${ }^{8}$.

Os efeitos e os riscos desse padrão de produção e consumo são ultra danosos: efeito estufa, chuvas ácidas, medo do estoque de artefatos nucleares, buraco na camada de ozônio, diminuição das florestas tropicais, mudanças climáticas, erosão. Ou, como diz um relatório da ONU, produzido no dia Mundial do Meio Ambiente, em junho de 1993: "Se todos os cinco bilhões de habitantes queimassem combustiveis fósseis (gasolina, diesel, querosene) na mesma taxa dos norte-americanos, além de provocar nossa própria asfixia, os esgotariam da noite para o dia. E se a todos fossem fornecidas apenas as 1.608 calorias por dia que um adulto médio de Moçambique consome - a Organização Mundial de Saúde (OMS) recomenda um minimo de 2.600 calorias por dia - miIhões morreriam, ou de inanição, ou na cruel luta pelos recursos que, inevitavelmente, se sucederia. A longo prazo, teremos, ou igualdade, ou nossa própria destruição".

E para isso não há soluções triviais, fáceis. Há que se perguntar quantos empregos dependem da manutenção deste sistema perdulário? E quanto tempo ele ainda tem condições de continuar existindo? Desse modo, o peso enorme, atualmente, que um sistema econômico avançado coloca sobre os sistemas ecológicos está se tornando insustentável, ou chegando no seu limite. Assim, tudo leva a crer que a questão do desemprego irá se tornar cada vez mais, além de social, uma variável de natureza ambiental, que as empresas e os governos terão de lidar.

A Comissão Mundial sobre o MeioAmbiente e Desenvolvimento (CMMAD), em Nosso futuro comum define desenvolvimento sustentável como "aquele que atende às necessidades do presente sem comprometer as possibilidades das gerações futuras atenderem às suas próprias necessidades" 9 . Entre os principais objetivos das políticas ambientais e desenvolvimentistas derivados deste conceito de desenvolvimento sustentável, estão os seguintes: "retomar o crescimento; alterar a qualidade do desenvolvimento; atender às necessidades essenciais de emprego, alimentação, energia, água e saneamento; manter um nivel populacional sustentável; conservar e melhorar a base de recursos; reorientar a tecnologia e administrar o risco; incluir o meio ambiente e a economia no 
processo de tomada de decisóes ${ }^{\prime 10}$. O grande desafio será, portanto, o de criar novos paradigmas de desenvolvimento, onde a preservação do ambiente e a promoção de emprego se fertilizem reciprocamente formando um círculo virtuoso.

\section{SOLUÇÕES TRADICIONAIS}

As massas crescentes de desempregados e subempregados não poderāo ser tratadas através dos meios tradicionais, como é o caso do seguro-desemprego, sem agravar ainda mais a crise fiscal dos Estados. Não é por outra razāo que, vez por outra, surgem nos países desenvolvidos governos com programas para limitar os benefícios sociais, a exemplo de Reagan e Thatcher.

A solução assistencialista dos países ricos europeus, através da estrutura previdenciária estatal, não deverá conseguir os recursos necessários, dos que trabalham, para sustentar crescentes números de desempregados, principalmente quando estes atingirem números elevados, como são os que já se observam hoje. A melhor saída, obviamente, é a do equilíbrio, da distribuição eqüitativa de trabalho e rendimentos dentro das populações economicamente ativas daqueles países.

Aparentemente, há também a possibilidade para a geração de novos empregos com a diminuição das jornadas de trabalho, outra medida tradicional para enfrentar o desemprego. Segundo Sachs ${ }^{11}$, a Alemanha e a França caminham para que os operários industriais cheguem no fim do século com 20 horas de trabalho por semana. A VW alemã está implantando o trabalho semanal de quatro dias. A partir de janeiro deste ano, os 100.000 empregados da VW estão trabalhando somente quatro dias na semana, o que representa uma redução de $20 \%$ no trabalho total. Para que isso fosse possivel, esses trabalhadores renunciaram a $10 \%$ do salário, o que contribuiu para assegurar 30 mil empregos ameaçados de extinção ${ }^{12}$. Em 1993, ela demitiu 7.000 funcionários. Se lembrarmos que o nível de produção não tem caído com o aumento do desemprego nesses países, a solução do conflito desemprego versus diminuição da jornada deverá pender para a segunda alternativa, seguindo o processo histórico.

A redução da jornada de trabalho também tem suas dificuldades na solução do problema em tela. Seiffer ${ }^{13}$ mostra que na ex-República Federal da Alemanha, onde ocorreram substanciais reduções da jornada durante o período de 1985-90, apenas $20 \%$ dos novos empregos gerados neste período podem ser atribuídos a essa redução. Para Neifer-Dichmann ${ }^{14}$, essa política representou um fracasso como forma de ampliar o emprego nesse país, pois os trabalhadores preferem trabalhar mais e ganhar mais, do que disporem de mais tempo livre. O mesmo parece estar ocorrendo nas montadoras brasileiras de veículos, onde o aumento recente da produção se deve mais ao aumento do número de horas extras do que ao aumento dos postos de trabalho. Provavelmente, esses fatos ocorrem devido ao padrão de consumo estimulado pelas próprias empresas, daí a necessidade de mudar esse padrão, conforme recomenda a Agenda 21 já mencionada. Além disso, essa autora entende que a redução da jornada teve efeitos localizacionais adversos para o país, contribuindo para expulsar empreendimentos para outras regiōes, onde as jornadas eram maiore $^{15}$. Essas constatações mostram que os problemas do crescente desemprego não podem ser resolvidos isoladamente, pois trata-se na verdade de problemas de dimensão planetária. Mostram também que os expedientes tradicionais já não são mais eficazes quando o desemprego atinge as cifras mostradas no início deste trabalho.

Dentro do conceito de desenvolvimento sustentável não cabem grupos excluídos ou marginalizados. Mesmo assistidos pelo Estado, ou por organizações da sociedade civil, os desempregados continuarão sendo excluídos e marginalizados do processo de desenvolvimento sustentável. Para as sociedades que passaram a encarar o trabalho como um valor em si, desde as suas origens históricas, o desemprego

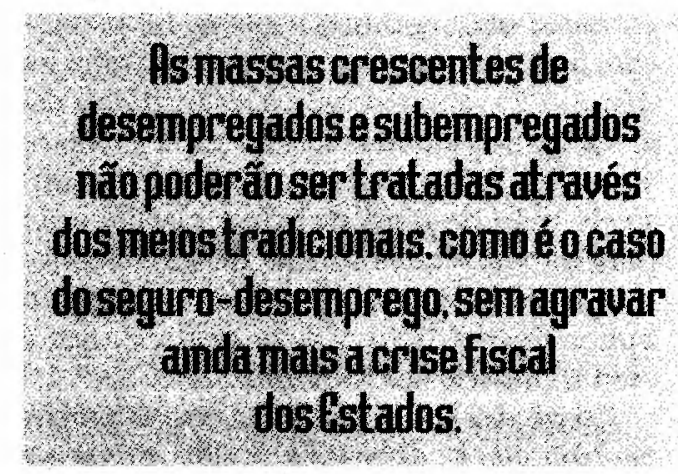

10. Idem, ibidem. p.53, grifo nosso.

11. SACHS, Ignacy. "Agenda 21, desemprego e desenvolvimento". Palestra realizada na EAESP/FGV em 26-10-1993.

12. ORTH, Martin. Tempo flexível de trabalho: só uma palavra da moda? Deutschland, n. 12, p. 14, 1994.

13. SEIFER, Hartmut. Efectos de la redución de la duración del trabajo sobre el empleo en la exRepública Federal Alemania. Revista Internacional de/ Trabajo, Genebra, OIT, v. 3, n. 1, p.72-3, 1992.

14. NEIFER-DICHMANN, EIisabeth. El equivoco de la redución del tiempo de trabajo em la ex-República Federal de Alemania. Revista Internacional del Trabajo, Genebra, OIT, v. 3, n. 1, p. 91, 1992.

15. Idem, ibidem, p.91-2. 
16. CMMAD. Op. cit., p.123

17. Idem, ibidem

18. LEWIS, W. A. Economic Development with Unlimited Supplies of Labor, 1954 in AGARWALA, A.N., SINGH, S.P. (orgs.) The Economics of underdevelopment. New York: GALAXY, 1963.

19. SACHS, Ignacy. Estratégias de transição para o sécu$10 X X I$. São Paulo: Studio Nobel \& FUNDAP, 1993. p.22. pode se constituir num modo de exclusão, tão ou mais cruel e ultrajante do que qualquer outro baseado em raça, credo, deficiência ou enfermidade. $E$ vale dizer que, sem a reafirmação permanente desse valor, não há como sustentar um ambiente empresarial. Assim, as empresas devem começar a considerar em seus processos de gestão meios para combater o desemprego com todos os males que ele provoca. Mais do que isso, devem começar a encarar o combate ao desemprego como uma de suas missões. A responsabilidade social da empresa não se esgota na produção de bens e serviços úteis à humanidade, respeitando o meio físico e a sua carga limitada de recursos. O processo de produção não pode gerar excluídos ou marginalizados, sob pena de comprometer a sustentabilidade em todas as suas dimensões: física, econômica, social e cultural.

Como mostrado acima, as práticas econômicas tradicionais procuram o aumento da "micro-produtividade" dentro de cada estabelecimento produtivo, provocando o desemprego, e o "macro-desperdício" com o consumo perdulário dos descartáveis e supérfluos para mantê-los. É irracional do ponto de vista da sustentabilidade ecológica e social. É preciso, portanto, buscar caminhos alternativos para o desenvolvimento. $\mathrm{O}$ Brasil pode se tornar um exemplo de como se chegar a um desenvolvimento sustentável, com base em sua exuberante natureza e a sua quantidade de recursos humanos e materiais.

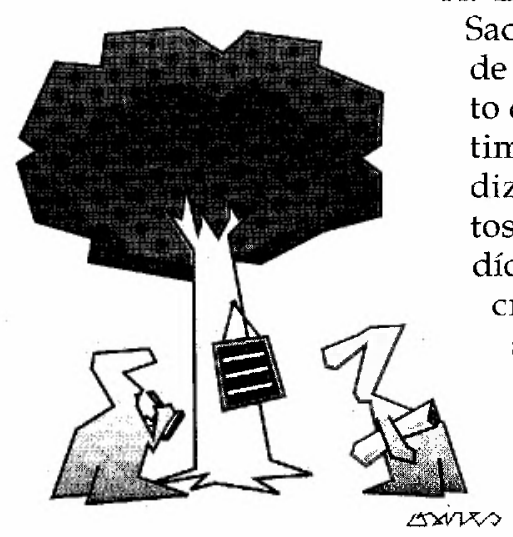

O desperdício maior aqui é primário, na extração dos insumos básicos, na produção, no transporte, no armazenamento, na disposição dos resíduos. Desperdícios estes já pouco existentes nos países desenvolvidos. Por outro lado, temos um excesso de mão-de-obra de baixa qualificação para as atividades típicas de uma economia desenvolvida, o que mostra que o maior desperdício que se pratica aqui é com o próprio ser humano.

Como diz o CMMAD, "um sério problema com que se defrontam muitos países é o desemprego generalizado e a inquietação daí decorrente. Muitas vezes a educação não consegue capacitar as pessoas a obterem empregos adequados" ${ }^{16}$. Ainda conforme o CMMAD, "a educação e a formação profissional deveriam também visar à aquisição de conhecimentos práticos e de técnicas profissionalizantes, $e$, principalmente, a aumentar a autoconfiança pessoal. Tudo isso deveria ser apoiado por esforços no sentido de fortalecer o setor informal e incrementar a participação de organizações comunitárias" ${ }^{\prime 1}$. São exemplos desse tipo de trabalho as iniciativas do CEMPRE (Compromisso Empresarial pela Reciclagem) e do SENAI (Serviço Nacional de Aprendizagem Industrial) para formar cooperativas de catadores, com base na experiência bem-sucedida da COOPAMARE (Cooperativa dos Catadores Autônomos de Papel, Aparas e Materiais Reaproveitáveis) em São Paulo.

O casamento dos recursos humanos abundantes com o aproveitamento de desperdícios, inclusive de recursos naturais, pode se tornar um mecanismo de sustentação ecológica e de empregos no Brasil. A idéia remonta aos anos $50 \mathrm{com}$ o clássico, Economic Development with Unlimited Supplies of Labor, de W. A. Lewis ${ }^{18}$. Kaleki, segundo Sachs ${ }^{19}$, assinalava a validade das fontes de crescimento que não envolvam investimentos, ou, poderíamos dizer, grandes investimentos. A eliminação do desperdício libera recursos para o crescimento econômico, sem exigir mais insumos.

E, continua Sachs, a reciclagem de resíduos, a conservação de energia e da água e a manutenção do estoque de equipamentos e das infra-estruturas são intensivas em mão-de-obra, criando empregos autofinanciados pelas economias realizadas na utilização de matérias-primas. Este é um campo ainda inexplorado de oportunidades de emprego, onde considerações sociais, econômicas e ambientais seguem juntas, c oferecem um ponto de partida conveniente para o planejamento de estratégias de ecodesenvolvimento urbano e rural.

Dentro desta perspectiva, o Brasil apresenta inúmeras oportunidades de ala- 
vancar empregos através da eliminação dos desperdícios. Exemplos de desperdícios encontram-se por toda a parte: no precário armazenamento e transporte das safras agrícolas; no desmantelamento das ferrovias e rodovias, que aumentam os acidentes, as mortes e os fretes; no aproveitamento insuficiente de águas subterrâneas e dos rios perenes para irrigação; na pouca exploração do potencial turístico, principalmente no Norte e Nordeste, e do ecoturismo; nos poucos programas de aproveitamento das biomassas; na deficiência da construçāo civil de residências; no subdesenvolvimento da piscicultura interna; na má difusão de modernas tecnologias agrícolas de pequena escala e mão-de-obra intensiva; na quase inexistente reciclagem ou reaproveitamento do lixo urbano ou dos resíduos industriais etc.

As possibilidades de gerar empregos com práticas sustentáveis são inúmeras. Não cabe neste trabalho discuti-las em detalhe, mas sim constatar o grande potencial de geração de empregos que pode ocorrer através de soluções locais de combate ao desperdício, tanto nos grandes centros urbanos, quanto no interior e nas áreas rurais mais distantes. A Fundação João Pinheiro de Belo Horizonte estimou que, da safra agrícola de 73,6 milhões de toneladas de cereais colhidas no Brasil em 1994, cerca de 15,4 milhões deverão se perder entre a fazenda e a agroindústria ${ }^{20}$. Para um país que possui cerca de 32 milhões de miseráveis, um desperdício dessa ordem é algo intolerável. Quantos empregos poderiam ser gerados para proteger e processar esses alimentos perdidos?

Não se trata, evidentemente, de propor um modelo de desenvolvimento que exclua as modernas técnicas de produção baseadas nas novas tecnologias. Mas sim reconhecer que há lugar para tecnologias alternativas, intensivas em trabalho e que ao mesmo tempo contribua para a geração de um ambiente produtivo dinâmico. Ou como diz Sachs ${ }^{21}$ : "Uma cuidadosa seleção dos casos em que é necessária a aplicação de altas tecnologias deve-se associar à exploração das inúmeras oportunidades para se resolverem problemas por meio da criatividade organizacional, de técnicas simples e de parti- cipação popular". Por exemplo, poucas empresas grandes do Nordeste comandam a produção e exportação de frutas típicas da região. Poderiam haver pacotes tecnológicos para grandes e pequenos produtores cooperativados. $O$ verde das plantaçōes irrigadas faria muitos voltarem para o seu sertão, com melhores condiçōes de vida, $\mathrm{e}$ melhoraria a paisagem ambiental. Outro exemplo: frentes permanentes de trabalho para a conservação de estradas (inclusive vicinais), açudes etc. ajudariam a diminuir a erosão e a conservar o ambiente e os recursos produtivos, ao mesmo tempo que permitiria fixar trabalhadores no campoe nas pequenas cidades.

Os exemplos podem ser infindos. $\mathrm{O}$ importante a ressaltar é que um modelo de desenvolvimento sustentável tem necessariamente que administrar o pluralismo tecnológico, principalmente num

\section{O casamento dos recursos humanos abundantes com 0 aprovertamento de desperdícios, inclusive de recursos naturaıs, pode se tornar um mecanısmo de sustentaçãa ecológlca e de empregos no Brasil.}

país como o nosso, onde existe um enorme contingente de pessoas excluídas de qualquer benefício do progresso material. Utilização de resíduos, reciclagem, aproveitamento de biomassas, construção e conservação da infra-estrutura produtiva, proteção às áreas de reserva ambiental, são algumas formas de simultaneamente proteger o meio ambiente e alavancar o emprego. Além disso, atividades como essas contribuem para dotar o sistema produtivo de condições mais eficientes para que as empresas possam obter competitividade em suas áreas de atuação. Esse cuidado com o meio ambiente e com o nível de emprego deve fazer parte da busca de uma competitividade sistêmica dentro de uma abordagem de desenvolvimento sustentável.

0940607
20. SAFRA 94 jaga no lixa US\$ 2.75 bilhões. Folha de São Pau10, São Paulo, 24 maio 1994. Caderno Agrofolha, p.1.

21. SACHS, Ignacy. Op. cit., p. 32. 